\title{
O Impacto da Utilização da Ferramenta Pivotal Tracker para Monitoração de Desempenho em Times Ágeis de Desenvolvimento de Software
}

\author{
Dorgival Netto $^{12}$, Ana de Holanda ${ }^{13}$, Flavio Neves ${ }^{1}$, Cloves Rocha ${ }^{1}$, Helena Bastos ${ }^{1}$ \\ ${ }^{1}$ Centro de Informática, Universidade Federal de Pernambuco \\ ${ }^{2}$ Instituto Federal de Mato Grosso do Sul, Campus Corumbá \\ ${ }^{3}$ Instituto Federal do Acre \\ \{dpsn2, acah, fsn2, car2, hcab2\}@cin.ufpe.br
}

\begin{abstract}
This research aims to analyze the influence that the performance monitoring tool Pivotal has on the relationship between the members of a development agile team. An ethnographic case study was conducted in a software development company, with the unit of analysis being team members and the project manager. We realize that the tool shares with all information, schedules, and performance of each team member, allowing everyone to follow the steps of the project. Also, the spirit of unity and knowledge sharing brings a sense of trust and satisfaction among the team members.
\end{abstract}

Resumo. Esta pesquisa visa analisar a influência que a ferramenta de monitoração de desempenho Pivotal tem na relação entre os membros de um time ágil de desenvolvimento. Foi realizado um estudo de caso de cunho etnográfico em uma empresa de desenvolvimento de software, tendo como unidade de análise os membros do time e o gerente de projetos. Identificamos que a ferramenta compartilha com todos as informações, cronogramas e desempenho de cada membro da equipe, permitindo que todos possam acompanhar as etapas do projeto. Além disso, o espírito de união e compartilhamento de conhecimento trazem a sensação de confiança e satisfação entre os individuos do time.

\section{Introdução}

Desenvolvedores de software de projetos que seguem os valores e princípios enunciados no Manifesto Ágil, quando estão devidamente motivados e capacitados, a partir de excelência técnica e design simples, passam a criar valor de negócio e a entregar softwares funcionais a intervalos cada vez mais curtos e regulares (Dingsøyr, 2012).

Para facilitar a implementação de projetos ágeis, pode-se utilizar ferramentas de planejamento e monitoração como, por exemplo, a Pivotal Tracker ${ }^{1}$. A ferramenta exibe uma lista priorizada de estórias que o time está trabalhando, todas as estórias que o Product Owner priorizou e, as estórias não priorizadas. A utilização de uma ferramenta de monitoração de desempenho permite o compartilhamento mútuo de informações, anseios, expectativas e desafios enfrentados pelos membros do time.

\footnotetext{
${ }^{1}$ https://www.pivotaltracker.com/
} 
Portanto, é necessário investigar, em um cenário real, como os desenvolvedores de software se sentem quanto à exposição do seu desempenho para toda a equipe. Assim, nossa pergunta de pesquisa visa investigar "Como o uso de ferramentas que dão suporte a métodos ágeis para monitoração de desempenho, em projetos de software, podem influenciar na relação entre indivíduos da equipe".

Diante disso nossa pesquisa teve o objetivo de identificar como os desenvolvedores de software se sentem ao terem seu desempenho monitorado e divulgado para todos da equipe. Na empresa avaliada, verificamos que a ferramenta que dá suporte a metodologia ágil tem influência positiva na relação de confiança e colaboração entre os membros do time.

\section{Trabalhos Relacionados}

Araújo (2014) visa identificar como gerentes formam equipes de software em organizações públicas, a fim de descobrir os critérios, bem como entender de que modo eles são utilizados. O autor identificou que a maior parte dos critérios para formar equipes de software pertencem à categoria dos fatores individuais e é necessário gerenciar a influência que isso pode causar para a equipe de uma forma geral.

França et al. (2013) aborda a motivação como sendo um fator muito importante que precisa ser analisado em uma equipe de desenvolvimento de software. A pesquisa demonstra que a sinergia no trabalho em equipe pode influenciar no desempenho individual e comprometimento. Entretanto, a natureza repetitiva de tarefas, a alta carga de trabalho é vista como um fator que causa a desmotivação entre os membros do time.

Assim, verificamos a importância em pesquisar de que forma os membros da equipe de desenvolvimento de software se relacionam com os outros membros diante da utilização da monitoração do desempenho de suas atividades.

\section{Metodologia}

\subsection{Design do estudo}

Utilizamos uma abordagem de pesquisa qualitativa, pois estamos interessados em compreender o problema de pesquisa em um contexto particular (Merriam, 2015). Esta pesquisa possui uma abordagem através do estudo de caso com cunho etnográfico e entrevista semiestruturadas em uma empresa de desenvolvimento de software. Um estudo de caso foi escolhido porque pode ser conceituado como uma descrição e análise intensiva de um indivíduo, grupo, instituição ou comunidade (Merriam, 2015). E tem cunho etnográfico porque procuramos observar o comportamento de um grupo particular de pessoas.

\subsection{Amostra dos Participantes}

A unidade de análise do estudo é composta por seis desenvolvedores e um gerente de projetos que estão inseridos em, pelo menos, uma equipe e trabalham com métodos ágeis. A amostra pode ser caracterizada como não probabilística, pois a seleção dos elementos da população depende ao menos, em parte, do julgamento do pesquisador e, podemos escolher casos ricos para o estudo (Merriam, 2015).

\subsection{Preparação da Coleta}


Inicialmente, foram realizadas observações da amostra, procurando acompanhar as atividades diárias dos times para entender a sua cultura e comportamentos no seu ambiente profissional. Entrevistas semiestruturadas foram realizadas, utilizando roteiros especificamente concebidos e compostos de perguntas abertas. Os roteiros foram pré-testados, através de uma entrevista piloto com um dos desenvolvedores da empresa.

Estas experiências ajudaram a refinar os roteiros de entrevista do Gerente de Projetos $^{2}$ e dos desenvolvedores ${ }^{3}$. Após a realização das entrevistas, ocorreu a transcrição, codificação e categorização dos dados. Também realizamos entrevistas de retrospectiva para clarificar e complementar as informações identificadas na análise dos dados. Após isso, também foi disponibilizado um diário ${ }^{4}$ para que as atividades dos desenvolvedores fossem registradas durante uma semana (segunda-feira a sexta-feira).

\subsection{Análise de Dados e Síntese}

$\mathrm{Na}$ análise dos dados, seguimos diretrizes fornecidas por Strauss e Corbin (2008) para categorizar e sintetizar dados, para construir uma teoria baseada em evidências de como os membros de um time ágil se relacionam com a utilização de ferramentas de monitoração de desempenho. O áudio das entrevistas foi transcrito e o QSR NVIVO ${ }^{5}$ foi usado para apoiar o processo de análise. Nós consideramos porções rotuladas de texto usando códigos e em seguida estes códigos foram relacionados dando origem às categorias que foram nomeadas seguindo um método de comparação constante (Strauss e Corbin, 2008). A Figura 1 mostra o processo de criação de uma categoria. Em seguida, as relações entre categorias foram mapeadas, levando a proposições explicativas que sustentam a estória central. Os dados foram discutidos em grupo durante reuniões e inconsistências identificadas foram tratadas tanto nas discussões quanto em explicações complementares dos participantes.

\section{Resultados e Discussões}

\subsection{Descrição do contexto}

O estudo foi realizado em uma empresa de software localizada em João Pessoa-PB, especializada no desenvolvimento de soluções para o acolhimento e o processamento de dados através de sistemas sob o conceito de SaaS (Software as a Service). Estas soluções são desenvolvidas nas linguagens de programação: Python, Java, C e Go. O processo de desenvolvimento ágil é baseado no Scrum, com times pequenos, reuniões diárias, participação do cliente, utilização de backlog, sprints com duração de 15 dias.

\subsection{Coleta de Dados}

As entrevistas foram realizadas com sete participantes nas instalações da empresa. Todas as entrevistas foram gravadas e juntas totalizaram 3:52h de tempo de áudio.

\footnotetext{
${ }^{2}$ Roteiro de entrevista do Gerente de Projetos: https://bit.ly/2Zu3ptI

${ }^{3}$ Roteiro de entrevista do Desenvolvedor: https://bit.ly/2NzAq5A

${ }^{4}$ Diário: https://bit.ly/33ZNoiF

${ }^{5}$ https://www.qsrinternational.com/nvivo/home
} 


\subsection{Relacionando fatores e construindo hipóteses}

Em seguida, traçamos as relações entre os fatores que influenciam o relacionamento dos

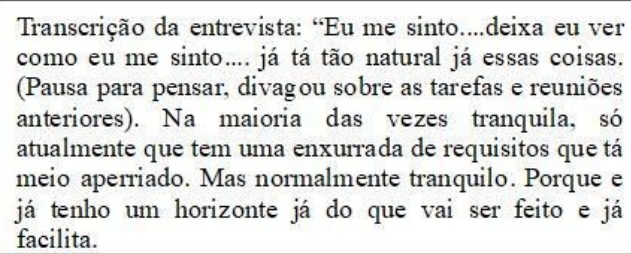

Transcrição da entrevista: "Eu me sinto.....deixa eu ver como eu me sinto.... já tá tão natural já essas coisas.

(Pausa para pensar, divag ou sobre as tarefas e reuniões anteriores). Na maioria das vezes tranquila, só atualmente que tem uma enxurrada de requisitos que tá meio aperriado. Mas normalmente tranquilo. Porque e já tenho um horizonte já do que vai ser feito e já facilita.

Rapaz, eu fico naquela de saber como é que eu fui.. mas, até agora tá tranquilo, mas a gente sempre fica na ansiedade de saber como foi além do meu..... porque assim, esqueci de te falar, na verdade a gente tem a pontuação de tarefa de cada membro, só que a gente não fica aqui todos os dias... entendeu, assim, olhando não dá tempo de fazer a soma, a gente só sabe a soma de pontuação de cada um na reunião. Ai a gente fica na ansiedade para saber quem tá na frente... entendeu?

\section{Categoria:}

Sentimentos

na avaliação da Sprint

Figura 1. Construção de uma categoria por meio de codificação aberta

membros da equipe com a ferramenta. Nós construímos as proposições, organizando e conectando os elementos mais fortes da teoria, mas também, apresentando uma visão particular do fenômeno na empresa.

Proposição 1: A maneira como o processo ágil da empresa está organizado auxilia na utilização da ferramenta como principal artefato do método ágil.

Proposição 2: A transparência é um dos pilares do método ágil Scrum, o fato da empresa utilizar uma ferramenta que permita aos membros da equipe uma visão geral do projeto e conhecimento do que cada um está fazendo, influencia no bom relacionamento entre os membros da equipe.

Proposição 3: As reuniões de planejamento da sprint e as reuniões diárias definem a distribuição das tarefas, o acompanhamento das atividades e o andamento da realização das tarefas. Estes são critérios determinantes para a avaliação de desempenho. O fato da empresa ter uma ferramenta capaz de gerenciar esses critérios faz com que a equipe tenha uma boa satisfação em relação a ferramenta.

Proposição 4: A reunião de avaliação de desempenho causa, aos membros da equipe, tensão antes da reunião e tranquilidade após a reunião.

Proposição 5: Os problemas de especificação prejudicam o desempenho individual e da equipe. Mas, este fator pode ser reduzido devido ao bom relacionamento entre os membros da equipe que gera confiança e aumenta o desempenho.

\subsection{Construção da estória central do caso}

A Figura 2 apresenta a estória central. Nós usamos retângulos para representar as categorias, paralelogramos para aspectos intangíveis, linhas tracejadas para agrupar as categorias centrais e, setas para representar a forma como os fatores influenciam 


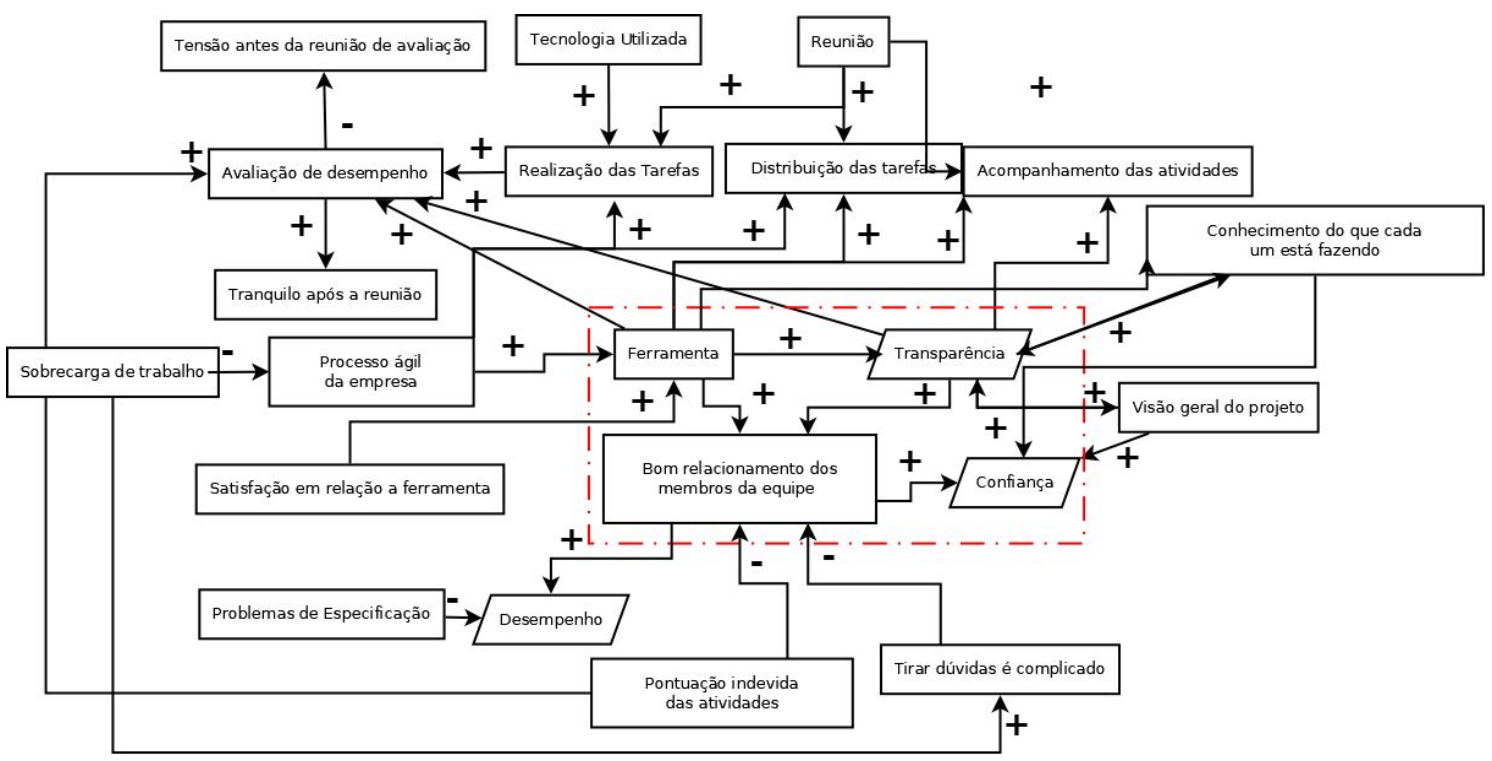

Figura 2. Estória central da pesquisa

(positiva + e negativamente -) o relacionamento entre os indivíduos de um time que utiliza ferramenta para monitoração de desempenho em projetos de software.

A implantação do processo de desenvolvimento de software, baseado nos métodos ágeis, foi fruto da iniciativa dos colaboradores e foi bem aceita pela Diretoria que decidiu patrocinar uma consultoria especializada na implantação de metodologias, adquirir uma ferramenta que suportasse esse processo e realizar o treinamento de todas as equipes no processo e na ferramenta. Como pode ser demonstrado no trecho abaixo:

- "Não tinha como dar prazo real para o dono da empresa. Hoje dá pra dar um prazo mais real com essa forma de monitoramento. Foi uma evolução grande pra gente. Como eu tô desde o início, era meio solto mesmo" (Entrevistado 1).

- "Fomos nós que escolhemos a ferramenta e pedimos para que fosse adquirida. O processo foi elaborado por todos nós. Ficamos muito motivados com a utilização do processo ágil" (Entrevistado 2).

Após a implantação da metodologia e da adoção da ferramenta Pivotal como meio do gerenciamento e monitoramento das atividades dos projetos, as equipes passaram a utilizá-la durante as suas atividades diárias. Como afirma o Entrevistado 4: "Todos usam muito bem a ferramenta. Não teve resistência na implantação".

Assim, após a análise das transcrições das entrevistas percebemos dois cenários.

Primeiro Cenário: Neste cenário percebemos que com as reuniões diárias e os acompanhamentos quinzenais, onde todas as atividades e resultados obtidos eram devidamente registrados na ferramenta, a comunicação do grupo melhorou substancialmente e também aumentou o conhecimento das tecnologias utilizadas.

Como todas as atividades distribuídas para a equipe eram registradas na ferramenta, bem como sua pontuação e acompanhamento, aumentou a transparência do andamento do projeto e do desempenho da equipe, realizados nas reuniões diárias e quinzenais. Possibilitando uma maior sinergia entre os membros da equipe, melhorando o relacionamento, o nível de confiança e tornando-os mais motivados. 
As categorias centrais da pesquisa, apresentadas na Figura 2, demonstram que a partir da boa relação da equipe, do acompanhamento através da ferramenta surge a transparência e a confiança necessária para que todos possam agir de forma colaborativa. Relatos das entrevistas podem corroborar com esta afirmação.

- "É a troca de experiência entre os membros da equipe e com as outras equipes. Estou ganhando experiência com meus companheiros em várias tecnologias. Estou aprendendo muito e é isto o que eu mais gosto" (Entrevistado 5).

- "Todo mundo se ajuda mesmo trabalhando em projetos distintos. Conhecemos as mesmas ferramentas. Na outra empresa que eu trabalhava era cada um por si. Ninguém se ajudava. Gosto muito do clima de trabalho" (Entrevistado 4).

- "A metodologia faz todo o processo de desenvolvimento ficar muito bem organizado, ninguém fica perdido, existem poucos atrasos" (Entrevistado 2).

Neste cenário, os membros da equipe veem a ferramenta como um meio que proporciona o acompanhamento das atividades e o conhecimento do que cada um está fazendo. Proporcionando uma visão geral do projeto e contribuindo para o bom relacionamento entre os membros da equipe e aflorando sentimentos como confiança e companheirismo. Aumentando, por sua vez, o desempenho individual e da equipe.

- "Vejo que fica tudo muito organizado. Todo mundo segue um padrão, reuniões diárias, tudo bem direitinho. A gente vê que a equipe fica bem centrada no projeto e consegue terminar no tempo certo" (Entrevistado 2).

- "O quadro e os post-its hoje estão na ferramenta. A ferramenta tem o backlog. Sem a ferramenta não deu certo, os post-it caiam do quadro no chão. Não era prático. Todos esses artefatos estão incluídos na ferramenta" (Entrevistado 5).

- "Fico ciente de como foi o desempenho de todos e penso o que eu poderia ter feito melhor em relação às tarefas e já penso nas novas tarefas"(Entrevistado $1)$.

Segundo cenário: Neste cenário, os membros da equipe começam a utilizar os conceitos da metodologia ágil como a outra equipe. Entretanto, devido à sobrecarga de trabalho, o processo não está sendo seguido. As reuniões diárias não estão ocorrendo e a distribuição das tarefas não estão sendo registradas na ferramenta.

- "A ferramenta é muito boa, porém não faz milagre. O trabalho depende mais das pessoas do que das ferramentas" (Entrevistado 3).

- "Atualmente não se está seguindo o processo.. As reuniões precisam voltar a acontecer. Existe uma sobrecarga de trabalho o que está prejudicando o trabalho porque nem todos são autogerenciados na equipe. As reuniões de feedback e desempenho são muito importantes para termos as métricas e termos o planejamento adequado" (Entrevistado 7).

Ao analisar a Figura 2, podemos visualizar que a carga de trabalho, problemas de especificação do projeto, a não realização das reuniões diárias e a falta de comunicação entre os membros da equipe podem influenciar negativamente no bom relacionamento da equipe, consequentemente no sentimento de confiança e desempenho da equipe. Os membros dessa equipe mostraram-se desmotivados com o fato do processo não estar sendo seguido e reclamaram da falta de conhecimento do 
planejamento do projeto, desconhecimento do desempenho da equipe e falta de transparência na gestão da equipe.

Cenário comum: Apesar das diferenças identificadas entre as duas equipes entrevistadas, tivemos um ponto em comum. Para ambas, a utilização de metodologia ágil na empresa é primordial para um maior acompanhamento das atividades do projeto de desenvolvimento de software. Também consideram a ferramenta um importante instrumento de monitoração e acompanhamento das atividades da equipe.

- "Hoje a reunião não está acontecendo como deveria. Quando acontecia a reunião, eu ficava muito tranquilo porque sou muito comprometido. A comunicação é muito rápida e mesmo que eu estivesse com algum atraso, meu gerente já sabia e eu já estava tratando" (Entrevistado 6).

- "Atualmente não se está seguindo o processo como deveria ser em todos os projetos. As reuniões precisam voltar a acontecer" (Entrevistado 7).

Também é consenso entre os dois cenários que a ferramenta realiza com eficiência a monitoração das atividades de cada membro da equipe e que veem de forma positiva a avaliação através de uma pontuação das atividades. Entretanto, o fato da subjetividade da definição do valor a ser pontuado é visto como algo que traz influências negativas e que podem impactar a relação de confiança e união identificados na equipe que está efetivamente utilizando a metodologia ágil em suas atividades. Segue alguns comentários que nos norteiam para essa percepção:

- "Não tem métrica estabelecida que eu conheça. Não consegui ver os resultados das métricas" (Entrevistado 7).

- Nós não temos tido problemas com essa forma de trabalho então fica difícil mudar" (Entrevistado 3).

Dessa forma, fica claro que é necessário haver uma maior atenção e relação ao estabelecimento de métricas e que estas sejam divulgadas para os membros da equipe, como forma de deixá-los cientes e de motivá-los dentro da empresa. Em contrapartida, o objetivo não é engessar o processo de avaliação dentro da empresa:

- "Cada projeto e cada equipe tem uma forma de trabalho diferente. Na metodologia ágil você não tem um padrão. A cada projeto muda a produtividade, a pontuação e a velocidade”. (Entrevistado 3)

\subsection{Construção da estória central do caso}

Nesta seção, brevemente, discutiremos como aplicar nossas descobertas em casos práticos. É importante notar que estas recomendações não foram testadas na prática, de modo que só ilustram como as estratégias podem ser derivadas a partir dos resultados de uma teoria explicativa. A integração dos resultados com outros estudos de caso poderia melhorar a nossa compreensão de como a ferramenta afeta as relações no time. A utilização dos diários pelos desenvolvedores não foi realizada da maneira como esperada. Portanto, não conseguimos utilizar as informações desse artefato nas percepções em relação ao processo. Portanto, a estória central poderia ser reinterpretada com base nos resultados destes testes.

Vale salientar que algumas práticas ágeis como reuniões diárias, o monitoramento do desempenho da equipe e a alocação das atividades com a ferramenta, 
tem atuado positivamente em direção a um comportamento motivado devido a transparência fornecida por essas práticas, o fortalecimento do trabalho colaborativo e a melhoria no relacionamento da equipe. Foi observado que o trabalho repetitivo em algumas fases dos projetos e os limites para as oportunidades de crescimento geram desmotivação. Estratégias de rotação de trabalho poderiam acomodar as diferentes aspirações individuais relacionadas com a variedade de tarefas. Combinado com o desenvolvimento de competências, esta estratégia também afetaria as necessidades de crescimento relacionados com a auto realização. Além disso, um plano formal de carreira, oferecendo ações de lucro ligado a resultados de desempenho, poderia criar mais oportunidades de crescimento interno, tornando a equipe mais comprometida com as metas de longo prazo da organização e evitar a rotatividade.

\section{Considerações finais e trabalhos futuros}

Neste artigo apresentamos os resultados de um estudo de caso qualitativo de cunho etnográfico onde investigamos como a utilização de ferramentas de monitoração de desempenho, em projetos ágeis, influenciam no relacionamento dos membros da equipe.

No primeiro momento, o processo foi implantado em todos os projetos e as equipes estavam motivadas. A realização de reuniões diárias e acompanhamentos quinzenais, onde todas as atividades, pontuações e resultados obtidos eram devidamente registrados na ferramenta, melhoraram, substancialmente, a comunicação do grupo, a obtenção da transparência do andamento do projeto e do desempenho da equipe. Possibilitando uma maior sinergia entre os membros da equipe, melhorando o relacionamento e o nível de confiança. Por outro lado, os membros de uma das equipe mostraram-se desmotivados com o fato das reuniões diárias não ocorrerem e a distribuição das tarefas não serem registradas na ferramenta.

Embora os resultados apresentados não devam ser considerados como sendo universalmente válidos, os princípios centrais da teoria e do método de pesquisa podem ajudar outros pesquisadores a reinterpretar a teoria em contextos específicos.

\section{Referências}

Araujo, F. O. Escolha e aplicação de critérios para formação de equipes de software: implicações para composição de personalidade.Universidade Federal de Pernambuco, 1-106, 2014.

Dingsøyr, T., Nerur, S., Balijepally, V., Moe, N. B. A decade of agile methodologies: Towards explaining agile software development, 2012.

França, A. C. C., Araújo, A. C. M. L., Silva, F. B. Q. Motivation of software engineers: A qualitative case study of a research and development organisation. 6th International Workshop on Cooperative and Human Aspects of Software Engineering. IEEE, San Francisco, 9-16, 2013.

Merriam, S. B., Tisdell, E. J. Qualitative research: A guide to design and implementation. John Wiley \& Sons, San Francisco, 2015.

Strauss, A., \& Corbin, J. Pesquisa qualitativa: técnicas e procedimentos para o desenvolvimento de teoria fundamentada. (Tradução Luciane de oliveira da Rocha). 2. ed., Porto Alegre: Artmed, 288, 2008. 